\title{
INDUÇÃO DE CALOS DE Ortophytum mucugense WAND. E CONCEIÇÃ̃o
}

\author{
Fernanda de Jesus Oliveira Bastos ${ }^{1}$; Andressa Priscila Piancó Santos Lima²; Alone \\ Lima-Brito ${ }^{3}$ J José Raniere Ferreira de Santana ${ }^{4}$ \\ 1. Bolsista PIBIC/FAPESB, Graduanda em Agronomia, Universidade Estadual de Feira de Santana, e-mail: \\ nandahhbastos@ hotmail.com \\ 2. Doutoranda em Recursos Genéticos Vegetais, Universidade Estadual de Feira de Santana, e-mail: \\ andressapianco@gmail.com \\ 3. Professora, Departamento de Biologia, Universidade Estadual de Feira de Santana, e-mail: lima_brito@yahoo.com.br \\ 4. Orientador, Departamento de Biologia, Universidade Estadual de Feira de Santana, e-mail: jose.raniere@gmail.com
}

PALAVRAS-CHAVE: Chapada Diamantina; Bromélia; Calogênese.

\section{INTRODUÇÃO}

Orthophytum mucugense é uma espécie endêmica da Chapada Diamantina - Ba, ocorre em rochas próximas a rios e cachoeiras, e por ter um endemismo restrito, ocorrendo apenas no município de Mucugê, e apresentar populações pequenas, é considerada ameaçada (LOUZADA; WANDERLEY, 2010).

A cultura de tecidos vegetais é uma alternativa viável para a propagação de $O$. mucugense, visto que há relatos de trabalhos de micropropagação desta espécie. A multiplicação in vitro tem como principal objetivo a produção de grande número de plantas em menor tempo possível, considerando os aspectos qualitativos das estruturas originadas (CHAVES, SCHUCH; ERIG, 2005). Esta etapa pode ser desenvolvida através da organogênese ou embriogênese, as quais ocorrem por duas vias distintas: a direta e a indireta.

$\mathrm{Na}$ organogênese indireta há a necessidade de desdiferenciação do explante, originando calo antes do estabelecimento das células competentes (BERTOZZO; MACHADO, 2010), portanto, por serem massa celulares indiferenciadas, os calos têm facilidade na regeneração in vitro (KERBAUY, 1997), e permitem a obtenção de elevada taxa de multiplicação.

Neste processo é importante o balanço entre auxina e citocinina. O 2,4 diclorofenoxiacético (2,4-D) é a auxina mais utilizada para calogênese (NOGUEIRA et al., 2007), pois tem como importante característica seu elevado efeito na indução da divisão celular e na formação de calos (HUANG et al., 2011). Já as citocininas induzem, na presença de auxinas, a divisão celular em calos (TAIZ; ZEIGER, 2013), sendo a benzilaminopurina (BAP) umas das mais utilizadas (GUERRA; NODARI, 2006).

Há relatos da multiplicação in vitro via organogênese direta de $O$. mucugense (BELLINTANI et al., 2008; LIMA et., al 2012), contudo os autores sugerem que sejam realizados outros estudos para obtenção de uma maior taxa proliferativa. Isto pode ser feito por estudos de organogênese indireta, que ainda não foram relatados para esta espécie, visto que em geral esta via potencializa a regeneração de brotos. Além disso, deve-se testar diferentes tipos de explantes oriundos de uma única planta para maximizar a taxa de multiplicação in vitro. Portanto, o objetivo geral deste trabalho foi promover a indução de calos organogênicos com a utilização do 2,4-D, BAP, e diferentes explantes de Orthophytum mucugense.

\section{MATERIAL E MÉTODOS}

\section{Material vegetal e estabelecimento in vitro}

Para obtenção do material vegetal foram utilizadas sementes de Orthophytum mucugense coletadas no Parque Municipal de Mucugê, em Mucugê - Bahia. O processo de desinfestação foi realizado conforme descrito por Bellintani et al. (2007).

\section{Efeito do 2,4-D e do BAP na indução de calos de $O$. mucugense.}


Plantas germinadas in vitro com 5 meses de idade foram utilizadas como fonte de explantes para realização do experimento. Os explantes foram inoculados em tubos de ensaio $(25 \times 150 \mathrm{~mm})$ contendo $15 \mathrm{~mL}$ de meio de cultura. O meio utilizado foi o MS $1 / 2$ contendo $30 \mathrm{gL}-1$ de sacarose e $7 \mathrm{gL}-1$ de ágar (meio básico). $\mathrm{O} \mathrm{pH}$ do meio foi ajustado para 5,8 antes da autoclavagem, sendo realizada à $121^{\circ} \mathrm{C}$ por 15 minutos.

Os explantes foliares (segmento apical, segmento mediano e segmento basal) e radiculares com $1 \mathrm{~cm}$ de comprimento, foram inoculados em meio de cultura básico acrescido de diferentes concentrações de 2,4 diclorofenoxiacético - 2,4-D (0,00;5,0;10,0;15,0;20,0 $\mu \mathrm{M})$ e BAP $(0,00 ; 2,5 ; 5,0 \mu \mathrm{M})$. O delineamento experimental foi inteiramente casualizado, com arranjo fatorial de $4 \times 5 \times 3$, sendo quatro tipos de explantes, cinco concentrações de 2,4$\mathrm{D}$ e três de BAP, totalizando 60 tratamentos, com cinco repetições por tratamento e cinco amostras por repetição. Cada amostra continha um explante. Para ambos os experimentos, após 60 dias da montagem, foram avaliadas as variáveis porcentagem de explantes com calo (\%EC), coloração e textura dos calos, e número de brotos por explante (NBE).

\section{Condições experimentais}

$\mathrm{O}$ experimento foi mantido em sala de crescimento com temperatura de $26 \pm 3^{\circ} \mathrm{C}$, e mantido no escuro.

\section{Análise dos dados}

Os dados foram submetidos à análise de variância (ANOVA) utilizando o programa estatístico SISVAR 5.1 (FERREIRA, 2003) e as médias analisadas por regressão ou comparadas pelo Teste de Tukey a 5\% de probabilidade.

\section{RESULTADOS}

Os explantes foliares apicais e medianos não apresentaram resposta morfogênica. Somente os explantes folha basal e raiz foram responsivos à formação de calos, portanto os resultados apresentados correspondem a estes dois explantes. Os calos apresentaram textura friável e coloração que variou do branco ao amarelo claro, e não foi observada a regeneração de brotos em nenhum dos tratamentos.

A análise de variância apresentou interação tripla altamente significativa $(\mathrm{p} \leq 0,01)$ entre BAP, 2,4-D e tipos de explante para a porcentagem de explantes com calo (\%EC). Observou-se que a folha basal apresentou diferença estatística significativa em relação à raiz quando se utilizou a concentração de 5,0 $\mu \mathrm{M}$ de BAP e presença de 2,4-D (Tabela 1). Já para o explante raiz houve diferença estatística significativa em relação à folha basal na ausência desta citocinina e presença de 2,4-D (Tabela 1).

Nota-se para o explante folha basal que na presença da auxina o aumento das concentrações de BAP promoveu um incremento na formação de calos, visto que na ausência desta citocinina as taxas obtidas foram baixas e ao adicioná-la ao meio de cultura houve aumento na \%EC, que apresentaram diferenças significativas nas concentrações de 2,5 e 5,0 $\mu \mathrm{M}$ de BAP em relação a ausência desta citocinina (Tabela 1).

Já quanto ao explante radicular a presença de BAP gerou uma redução na formação de calos apontada pela diminuição das médias apresentadas nas concentrações de $2,5 \mu \mathrm{M}$ e 5,0 $\mu \mathrm{M}$ de BAP ambas na presença de 2,4-D; sendo que também na presença dessa auxina, exceto na maior concentração, houve diferença estatística significativa entre as médias obtidas na ausência de BAP e na concentração de 5,0 $\mu \mathrm{M}$ do mesmo (Tabela 1).

Em relação ao efeito do 2,4-D no explante foliar, nota-se que independente da presença de BAP, na ausência desta auxina não ocorreu indução de calos, sendo que com a adição do 2,4-D houve formação de calo, que aumentou à medida que as concentrações foram elevadas até atingirem um ponto máximo a partir do qual a \% $\mathrm{EC}$ tende a diminuir seguindo o 
modelo de regressão quadrática (Figura 1A). Observa-se que as maiores taxas foram obtidas na concentração de 5,0 $\mu \mathrm{M}$ de BAP em função das concentrações de 2,4-D, resultando a maior taxa na concentração de $15 \mu \mathrm{M}$ dessa auxina (Figura 1A).

Tabela 1. Porcentagem de explantes com calo (\%EC) em função das concentrações de BAP, 2,4-D e do tipo de explante em segmentos foliares e radiculares de Orthophytum mucugense.

\begin{tabular}{cccc}
\hline \multicolumn{3}{c}{ FOLHA BASAL } \\
\hline $2,4-\mathrm{D} \mu \mathrm{M}$ & 0,0 & BAP $\mu \mathrm{M}$ & 5,0 \\
\hline 0,0 & $0 \mathrm{Ba}$ & 2,5 & $0 \mathrm{Ba}$ \\
5,0 & $32 \mathrm{Ab}$ & $0 \mathrm{Ba}$ & $84 \mathrm{Aa}^{*}$ \\
10,0 & $34 \mathrm{Ab}$ & $88 \mathrm{Aa}$ & $84 \mathrm{Aa}^{*}$ \\
15,0 & $28 \mathrm{ABb}$ & $84 \mathrm{Aa}^{*}$ & $92 \mathrm{Aa}^{*}$ \\
20,0 & $8 \mathrm{ABb}$ & $72 \mathrm{Aa}$ & $84 \mathrm{Aa}^{*}$ \\
\hline & $76 \mathrm{Aa}$ & \\
$2,4-\mathrm{D} \mu \mathrm{M}$ & $\mathrm{RAIZ}$ & 5,0 \\
\hline 0,0 & & $\mathrm{BAP} \mu \mathrm{M}$ & $12 \mathrm{Ba}$ \\
5,0 & 0,00 & 2,5 & $32 \mathrm{ABb}$ \\
10,0 & $12 \mathrm{Ba}_{10}$ & $16 \mathrm{Ba}$ & $33 \mathrm{ABb}$ \\
20,0 & $92 \mathrm{Aa}^{*}$ & $68 \mathrm{Aa}$ & $48 \mathrm{Ab}$ \\
\hline & $92 \mathrm{Aa}^{*}$ & $56 \mathrm{Ab}$ & $60 \mathrm{Aa}$ \\
\hline
\end{tabular}

Médias seguidas pelas mesmas letras, maiúsculas nas colunas e minúsculas nas linhas, não diferem entre si pelo teste de Tukey a 5\% de probabilidade de erro. *Indica diferença estatística significativa entre os explantes.
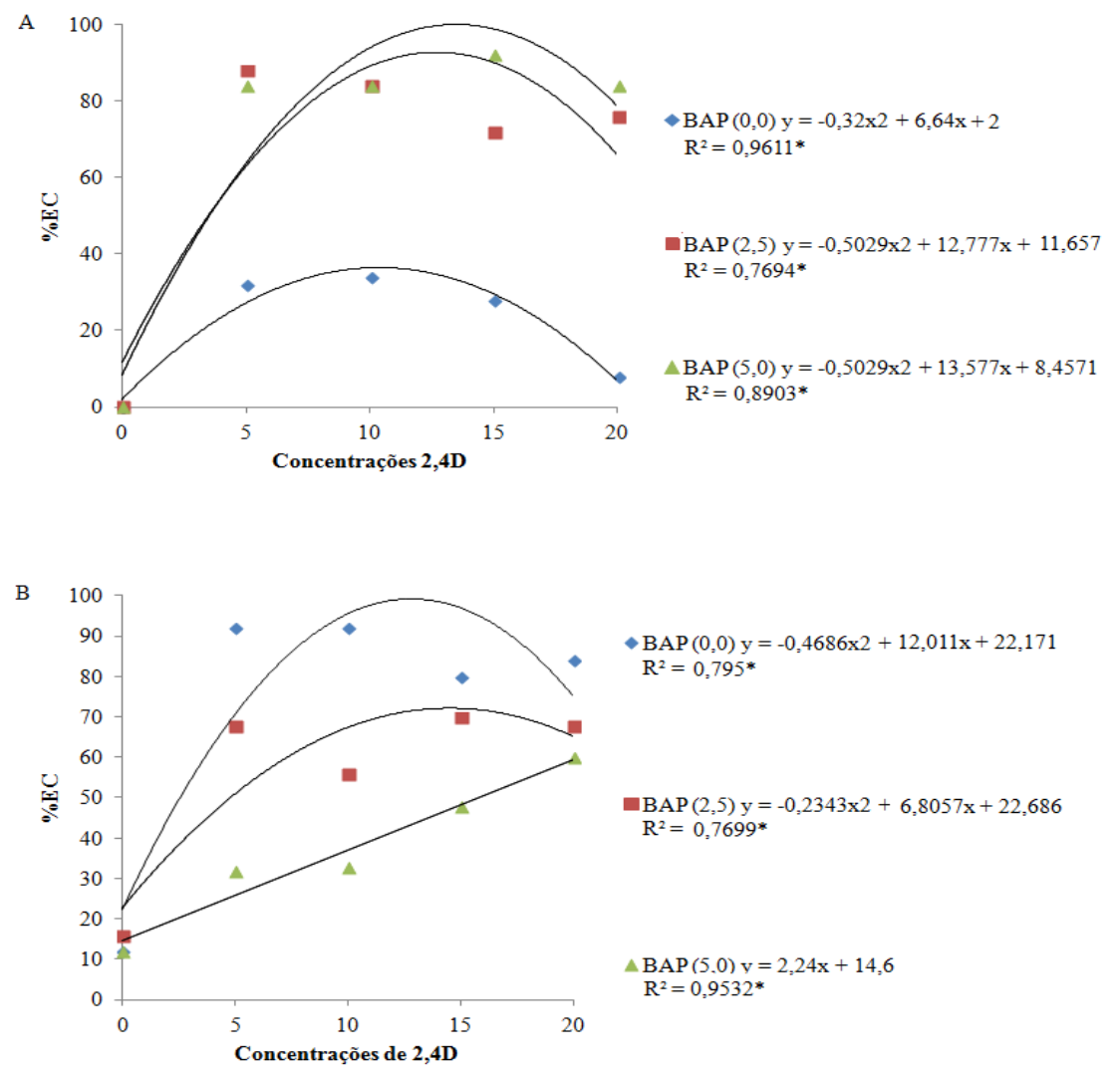

Figura 1. Porcentagem de explantes com calos (\%EC) em explantes foliares basais (A) e em explantes radiculares (B) em função de diferentes concentrações de 2,4-D e BAP. *Significativo a 5\% de probabilidade. 
Os pontos máximos de 10,37; 12,70 e 13,49 $\mu \mathrm{M}$ de 2,4-D calculados para 0,0; 2,5 e $5,0 \mu \mathrm{M}$ de BAP respectivamente, geraram os respectivos valores máximos estimados de $36,44 \%, 92,81 \%$ e $100 \%$, indicando que pode ser alcançada uma taxa de $100 \%$ de explantes responsivos à formação de calo.

Para o explante radicular, observa-se que o efeito do 2,4-D apresentou modelo quadrático de regressão na ausência e na concentração de $2,5 \mu \mathrm{M}$ de BAP, sendo que na concentração de 5,0 $\mu \mathrm{M}$ o modelo de regressão foi linear (Figura 1B). As \%EC mais elevadas foram geradas na ausência de BAP, sendo a maior delas obtida nas concentrações de $5 \mu \mathrm{M}$ e $10 \mu \mathrm{M}$ de 2,4-D, a partir da qual as taxas diminuem, e a curva entra em declínio a partir de 15 $\mu \mathrm{M}$ (Figura 1B).

$\mathrm{Na}$ ausência de BAP o ponto máximo para \%EC foi atingido na concentração de 11,07 $\mu \mathrm{M}$ de 2,4-D no qual o valor máximo estimado é de $97,71 \%$. Já na concentração de $2,5 \mu \mathrm{M}$ de BAP o ponto máximo foi de $14,52 \mu \mathrm{M}$ de $2,4-\mathrm{D}$ com valor máximo estimado de $72,10 \%$.

\section{CONCLUSÃO}

A combinação de $5 \mu \mathrm{M}$ de 2,4-D com 2,5 $\mu \mathrm{M}$ de BAP é indicada para indução de calos em explante foliar basal, e para o explante radicular é recomendado o uso isolado de $5 \mu \mathrm{M}$ de 2,4-D.

\section{REFERÊNCIAS}

BELLINTANI, M. C. et al. Estabelecimento in vitro de Orthophytum mucugense e Neoregelia mucugensis, bromélias endêmicas da Chapada Diamantina, Bahia - Brasil. Revista Brasileira de Biociências, Porto Alegre, v. 5, supl. 2, p. 1101-1103, jul. 2007.

BELLINTANI, M.C. et al. Resposta regenerativa in vitro de explantes caulinares de bromélias endêmicas da Chapada Diamantina- Bahia. Magistra, v.20, n.4, p.328-337, 2008.

BERTOZZO, F., MACHADO, I. S. Meios de cultura no desenvolvimento de ápices caulinares de mamoneira (Ricinus communis L.) in vitro. Ciência e Agrotecnologia, Lavras, v. 34, n. 6, p. 1477-1482, 2010.

CHAVES, A. da C.; SCHUCH, M. W.; ERIG, A. C. Estabelecimento e multiplicação in vitro de Physalis peruviana L.Ciênc. agrotec., v. 29, n. 6, 2005.

FERREIRA, D.F. SISVAR Sistema de análises estatísticas. Lavras: UFLA, v.3, n.4. 2003.

GUERRA , M. P.; NODARI, R. O. Introdução ao conceito de Biotecnologia. Edição da Steinmacher, 2006.

HUANG, P. L. et al. Micropropagation of bromeliad Aechmea fasciata via floral organ segments and effects of acclimatization on plantlet growth. Plant Cell, Tissue and Organ Culture (PCTOC), v. 105, n. 1, p. 73-78, 2011.

KERBAUY, G. B. Clonagem de Plantas "in vitro". Biotecnologia Ciência e Desenvolvimento. 1997.

LOUZADA, R. B.; WANDERLEY, M. das G. L. Revisionof Orthophytum (Bromeliaceae): the species with sessile inflorescences. Phytotaxa 13, 2010.

NOGUEIRA, R. C. et al. Indução de calos em explantes foliares de murici-pequeno (Byrsonima intermedia A. Juss.). Ciência e Agrotecnologia, v. 31, n. 2, p. 366-370, 2007.

TAIZ, L.; ZEIGER, E. Fisiologia Vegetal. 5. ed. São Paulo: Artmed, 2013. 